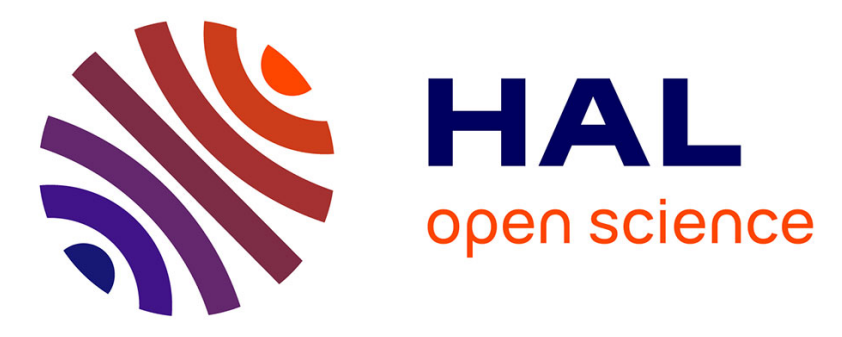

\title{
Scalable synthesis of ionic liquids: comparison of performances of microstructured and stirred batch reactors
}

\author{
Hicham Iken, F. Guillen, Hélène Chaumat, Marie-Rose Mazières, \\ Jean-Christophe Plaquevent, Théodore Tzedakis
}

\section{To cite this version:}

Hicham Iken, F. Guillen, Hélène Chaumat, Marie-Rose Mazières, Jean-Christophe Plaquevent, et al.. Scalable synthesis of ionic liquids: comparison of performances of microstructured and stirred batch reactors. Tetrahedron Letters, 2012, vol. 53 ( $\mathrm{n}^{\circ} 27$ ), pp. 3474-3477. 10.1016/J.TETLET.2012.04.119 . hal-01016015

\section{HAL Id: hal-01016015 https://hal.science/hal-01016015}

Submitted on 20 Jan 2022

HAL is a multi-disciplinary open access archive for the deposit and dissemination of scientific research documents, whether they are published or not. The documents may come from teaching and research institutions in France or abroad, or from public or private research centers.
L'archive ouverte pluridisciplinaire HAL, est destinée au dépôt et à la diffusion de documents scientifiques de niveau recherche, publiés ou non, émanant des établissements d'enseignement et de recherche français ou étrangers, des laboratoires publics ou privés. 


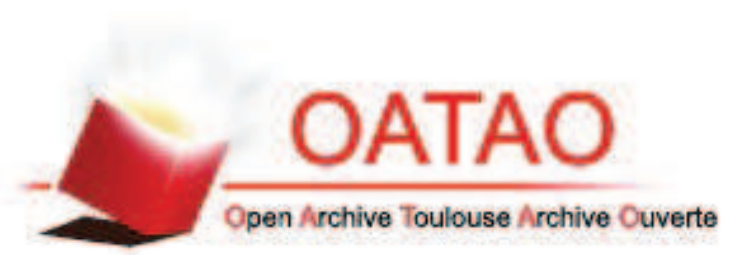

\section{Open Archive Toulouse Archive Ouverte (OATAO)}

OATAO is an open access repository that collects the work of Toulouse researchers and makes it freely available over the web where possible.

This is an author-deposited version published in: http://oatao.univ-toulouse.fr/ Eprints ID: 6067

To link to this article: DOI:10.1016/J.TETLET.2012.04.119

URL: http://dx.doi.org/10.1016/J.TETLET.2012.04.119

To cite this version: Iken, Hicham and Guillen, Frédéric and Chaumat, Hélène and Mazières, Marie-Rose and Plaquevent, Jean-Christophe and Tzedakis, Theodore (2012) Scalable synthesis of ionic liquids: comparison of performances of microstructured and stirred batch reactors. Tetrahedron, vol. 53 (n²7). pp. 3474-3477. ISSN 0040-4039

Any correspondence concerning this service should be sent to the repository administrator: staff-oatao@listes.diff.inp-toulouse.fr 


\title{
Scalable synthesis of ionic liquids: comparison of performances of microstructured and stirred batch reactors
}

\author{
Hicham Iken $^{\mathrm{a}, \mathrm{b}}$, Frédéric Guillen ${ }^{\mathrm{c}, \mathrm{d}}$, Hélène Chaumat ${ }^{\mathrm{a}, \mathrm{b}}$, Marie-Rose Mazières ${ }^{\mathrm{c}, \mathrm{d}}$, \\ Jean-Christophe Plaquevent ${ }^{\mathrm{c}, \mathrm{d}, *}$, Théodore Tzedakis ${ }^{\mathrm{a}, \mathrm{b}, *}$ \\ ${ }^{a}$ Université de Toulouse, INPT, UPS, Laboratoire de Génie Chimique, F-31062 Toulouse cedex 9, France \\ ${ }^{\mathrm{b}}$ CNRS, Laboratoire de Génie Chimique, F-31062 Toulouse cedex 9, France \\ ${ }^{\mathrm{c}}$ Université de Toulouse, UPS, SPCMIB,118 Route de Narbonne, F-31062 Toulouse cedex 9, France \\ d CNRS-UMR-5068, SPCMIB, 118 Route de Narbonne, F-31062 Toulouse cedex 9, France
}

\begin{abstract}
A B S T R A C T
A range of alkylpyridinium bromide ionic liquids have been synthesized in a stirred reactor at multigram scale and characterized by physical methods (viscosity, conductivity, melting point, electrochemical window, and water content). One ionic liquid, octylpyridinium bromide, was chosen to be synthesized in both macro and reduced scale reactors, in order to compare its performance and to afford evidence of the advantages of a cross channel micro reactor (channel width $=1 \mathrm{~mm}$ ) compared to a stirred reactor.
\end{abstract}

During the last decade, ionic liquids (ILs) became useful tools in organic, bioorganic, inorganic and analytical chemistry, owing to their several exceptional properties such as negligible vapor pressure, low melting point, high thermal stability and electrical conductivity, wide electrochemical window, and liquid range. ${ }^{1}$ ILs usually consist of large organic cations, such as quaternary ammonium, heterocyclic aromatic or pyrrolidinium, associated with a variety of non- or weakly coordinating anions. ${ }^{1}$ Their physicochemical properties arise from both the anion and the cation: this enables some tuning of the properties of ILs by varying the nature of the anion (respectively cation) for a given cation (respectively anion). ILs are new and promising solvents, particularly for catalysis, ${ }^{2}$ chiral syntheses, ${ }^{3}$ energy and separation processes, ${ }^{1 \mathrm{a}}$ where recycling of the solvent is highly desirable. ${ }^{4}$

Usually, the cationic parts are synthesized by alkylation, an exothermic reaction, and ILs are still produced at industrial scale in batch or semi-batch stirred reactors. This method is often strongly limited by the dissipation of the generated heat, because of the small interface between solution (in fact the chemical reaction sites) and the heat exchanger (double jacket, external or internal coil). Increasing this surface or the efficiency of the heat exchange (e.g., by reducing the distance between the heat exchanger and the

\footnotetext{
* Corresponding authors.

E-mail addresses: plaquevent@chimie.ups-tlse.fr (J.-C. Plaquevent), tzedakis@ chimie.ups-tlse.fr (T. Tzedakis).
}

chemical reaction sites, or/and combining the reaction area and the heater into a single device ${ }^{5}$ ) allows to improve the heat transfer, supplying or removing the heat almost as rapidly as it is generated by the reaction. Thus, it is possible to operate with a uniform temperature profile, avoiding any high temperature spot and therefore improving selectivity and conversion.

Chemical microstructured reactors (MSR) are devices containing open paths for fluids with dimensions in the submillimeter range. Mostly MSR have multiple parallel channels with diameters between 10 and several hundred micrometers, where the chemical transformation occurs; ${ }^{6}$ their main feature is the high surface to volume ratio, compared to more traditional chemical reactors. Accordingly, the heat transfer coefficient is inversely proportional to the channel size $\left(\mathrm{W} / \mathrm{m}^{2} \mathrm{~K}\right)$, and for liquids, it is one order of magnitude higher than in the traditional heat exchangers $;{ }^{7}$ so microstructures allow fast heating and cooling of reaction mixtures. Moreover, the easy transposition from lab processes to the industrial scale (by multiplying the number of microstructured reactors instead of scaling up a batch reactor), reinforces the reactivity against fluctuating market demand, and improves process safety by avoiding the use, during short durations, of large amounts of dangerous chemical intermediates.

Various studies describe the synthesis of ILs. ${ }^{1}$ While several recent reports proved the beneficial use of MSR for the synthesis of imidazolium-based ILs, ${ }^{8}$ to the best of our knowledge no other IL families have been studied. The first part of the present study de- 
scribes the multigram preparation and characterization of ILs constituted of alkylpyridinium cations (Fig. 1) substituted by various alkyl radicals, and bromide anion; a brief discussion on the effect of the cation size on the ILs physico-chemical properties is presented. Syntheses of the most representative IL were carried out both in a stirred classical reactor and in a heat exchanger/microstructured reactor (HEx/MSR), ${ }^{9}$ designed in our laboratory. Comparison of mass balance results for various conditions was performed in terms of conversion rate and selectivity, in order to evaluate the interest to use HEx/MSR at production scale.

The stainless steel heat exchanger/microstructured reactor (HEx/MSR) is composed of a plate $(250 \mathrm{~mm} \times 120 \mathrm{~mm})$ with rectangular $(1 \mathrm{~mm} \times 1 \mathrm{~mm})$ micro-channels (Fig. 2). The total volume of the microstructured plate (including inlet and outlet chambers) is $10.2 \mathrm{~cm}^{3}$. The specific area of the MSR is $S / V=251 / 10.2=24.6 \mathrm{~cm}$ ${ }^{-1}$. The reactants were introduced at $\mathrm{rt}$ into the reactor by a two syringe pump, and distributed over the micro-channels by appropriate geometry of the inlet channel. The appropriate shape and geometry of the inlet compartment allows a good mixing of reagents, so the solution was assumed to be homogeneous before reaching the reaction area (microchannels). A similarly designed collecting channel allows removing the reaction mixture.

We first embarked in the synthesis in batch reactor of a series of alkylpyridinium salts (Fig. 1); although most of them were already described in the literature, ${ }^{10}$ we needed to examine by ourselves a wide range of physico-chemical properties (Table 1 ) in order to select the best example for comparing synthetic performances of batch vs MSR. Experimental and analytical data are given in Supplementary data. The most significant properties for our studies are melting points and viscosity, which are directly relevant to IL behavior, and are discussed below.

Melting points of synthesized ILs are lower than the boiling point of water $\left(100^{\circ} \mathrm{C}\right)$ except for butylpyridinium bromide (Fig. 3). The phase transition temperature of ILs (from solid to liquid phase) is governed by Van der Waals and electrostatic interaction forces. ${ }^{11}$ The melting points fall steadily with increasing alkyl chain length from 4 carbons to reach a minimum value of $18^{\circ} \mathrm{C}$ for 8 carbons; when the carbon number exceeds 8 the melting points increase (Fig. 3). At the shortest chain length, the melting point is mainly governed by ionic interactions that decrease with the increase of the size of the cation: the melting point decreases when the alkyl chain length increases. However, at the longest chain length, Van der Waals interactions become prevalent, increasing the melting point. ILs are generally viscous liquids, and viscosity is mainly governed by Van der Waals interactions as well as intra or extra molecular $\mathrm{H}$ bonding. Higher length alkyl chain exalts these phenomena, ${ }^{12}$ and increases the viscosity due to reduced rotation freedom of the IL. Viscosity measurements were carried out versus shear rate for the synthesized ILs under two different experimental conditions: (1) at $5{ }^{\circ} \mathrm{C}$ above melting point for each IL; (2) at $110^{\circ} \mathrm{C}$, a temperature where all ILs are liquid. The viscosity increases with the number of carbon atoms in the alkyl group (Fig. 3). Worthy of note is that the viscosity of ILs containing a low carbon number alkyl group does not vary with increasing shear rate, depicting a Newtonian behavior. On the opposite, for [DoDePy][Br] and [OcDePy][Br], increase of the shear rate causes the viscosity to decrease asymptotically, which indicates a shear thinning behavior. Moreover, except for [OcPy] $[\mathrm{Br}]$, the increase

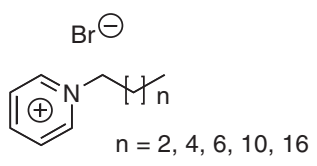

Figure 1. Structure of the alkylpyridinium salts. of temperature to $110^{\circ} \mathrm{C}$ leads to a significant decrease in the viscosity.

A strong influence of the temperature was observed in the case of [OcDePy][Br] (assumed to be a non-Newtonian IL), in comparison with the [OcPy][Br] (assumed to be a Newtonian IL). Arrhenius analysis allows to determine the viscosity activation energy: $37.9 \mathrm{~kJ} / \mathrm{mol}$ for [OcPy][Br] (Newtonian IL) and $17.2 \mathrm{~kJ} / \mathrm{mol}$ for [OcDePy] $[\mathrm{Br}]$ (non-Newtonian IL) and confirms the influence of the temperature in the case of the Newtonian IL.

In order to compare the performance of stirred reactor and HEx/ MSR, the synthesis of octylpyridinium bromide was chosen as the model reaction, because of the appropriate physical properties of this IL (low viscosity and melting point, non-hygroscopic behavior). Pyridine alkylation with 1-bromooctane was achieved under equimolar conditions and mass balances were performed under various operating conditions of temperature and residence time. The efficiency of both reactors for syntheses at the multigram scale was compared in terms of conversion rate by ${ }^{1} \mathrm{H}$ NMR.

In the stirred reactor, the operating procedure was as follows: the flask was charged with an equimolar amount of pyridine and 1-bromooctane $(0.10 \pm 0.01 \mathrm{~mol})$ under $\mathrm{N}_{2}$ atmosphere, and the stirred solution was heated to a fixed temperature using a preheated oil bath. When the reaction duration was reached, the flask was cooled to room temperature and then the content was diluted in chloroform-d to be analyzed by ${ }^{1} \mathrm{H}$ NMR. The first experiment was carried out at $60^{\circ} \mathrm{C}$ for reaction durations ranging from 0.8 to $4 \mathrm{~h}$. The results (Fig. 4(left)) show that the residual mole number of pyridine linearly decreases against the reaction duration. This means that the apparent reaction order of pyridine is zero, and the estimated reaction rate is constant and equal to $2.7 \times 10$ ${ }^{-5} \mathrm{~mol} \mathrm{~L}^{-1} \mathrm{~s}^{-1}$. During the reaction, the formation of IL involves the apparition of two distinct liquid phases: the lower phase comprises the IL and the upper one contains the residual reagents, which remain practically in the same concentration throughout the reaction because no mixing with the synthesized IL occurs. In order to validate these results, a second reaction was carried out at $70^{\circ} \mathrm{C}$. As expected, the decrease of residual mole number of pyridine was more important than at $60^{\circ} \mathrm{C}$. Compared to $60^{\circ} \mathrm{C}$, the conversion rate increases at least 2 times with a reaction rate of $7.9 \times 10^{-5} \mathrm{~mol} \mathrm{~L}^{-1} \mathrm{~s}^{-1}$, suggesting that the reaction is temperature limited under these conditions. The increase of the working temperature to $80^{\circ} \mathrm{C}$ led to a significant increase in the IL rate production with a reaction rate of $1.5 \times 10^{-4} \mathrm{~mol} \mathrm{~L}^{-1} \mathrm{~s}^{-1}$. For higher temperatures (Fig. $4\left(\right.$ left), curve at $100^{\circ} \mathrm{C}$ ), the evolution of residual mole number of pyridine versus time was not linear, indicating that the apparent reaction order of pyridine is not zero anymore. Higher temperature promotes the solubilization of pyridine within the IL, consequently the concentration of pyridine changes during the increase of the volume of synthesised IL. Conversion of pyridine reaches $90 \%$ after $4 \mathrm{~h}$ of reaction at this temperature. The estimated values of the apparent rate constant $\left(k_{\mathrm{app}}=k[\mathrm{Py}]^{1}[\mathrm{Alk}]^{1}\right.$, alkylation follows SN2 mechanism) allow access to the real rate constant of the alkylation. Arrhenius analysis of $k$ versus temperature led to the activation energy value of $85 \mathrm{~kJ} \mathrm{~mol}^{-1}$, a relatively high value.

As for the reaction in stirred reactor, the conversion rates of IL obtained with HEx/MSR were determined by ${ }^{1} \mathrm{H}$ NMR, and results are presented versus residence time in Figure 4(right). The increase of temperature from 60 to $100^{\circ} \mathrm{C}$ also involves an increase in the relative conversion rate, confirming that the reaction is temperature limited. The obtained curves $\left(n_{\mathrm{py}}=f(\tau)\right)$ at various temperatures are not linear indicating an apparent reaction order close to zero (order $=0.1$ ). Nevertheless, in almost all experiments, conversion rate were higher from HEx/MSR: for example at $1.3 \mathrm{~h}$ reaction time $n_{\mathrm{p} \text { Stirred R }} / n_{\mathrm{pMSR}}=1.04,1.08,1.12$ for respectively $60,70,80^{\circ} \mathrm{C}$, showing that the HEx/MSR was significantly more efficient than the stirred one. For temperatures higher than $100{ }^{\circ} \mathrm{C}$ there are no 

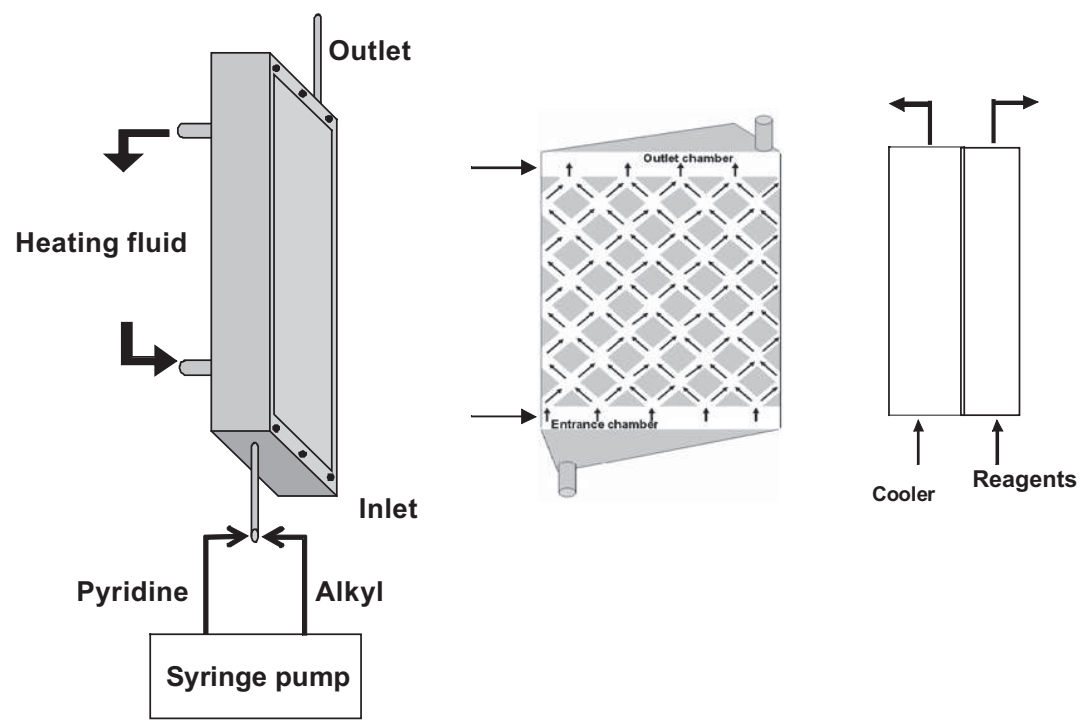

Figure 2. Left: Schematic representation of the heat exchanger/microstructured reactor: $V=10.2 \mathrm{~cm}^{3}, S / V=24.6 \mathrm{~cm}^{-1}$. Middle: Schematic shape of microstructured reactor. Right: the plate reactor seen from the side.

Table 1

Selected physico-chemical properties of alkylpyridinium bromides

\begin{tabular}{|c|c|c|c|c|c|}
\hline $\mathrm{R}$ & $\mathrm{Bu}$ & Hex & Oct & Dodecyl & Octadecyl \\
\hline Yield (\%) (a) & 80 & 87 & 79 & 67 & 77 \\
\hline $\operatorname{Mp}\left({ }^{\circ} \mathrm{C}\right)$ & 105 & 36 & 18 & 56 & 74 \\
\hline Water content (\%) & 1 & 1.6 & 1.7 & 1.3 & 1.2 \\
\hline Density $\left(\mathrm{g} / \mathrm{cm}^{3}\right)$ & 1.26 & 1.18 & 1.11 & 1.06 & 0.93 \\
\hline Conductivity $\chi$ at $110^{\circ} \mathrm{C}(\mathrm{mS} / \mathrm{cm})$ & 10.0 & n.e. & 8.4 & 1.7 & 1.0 \\
\hline Conductivity $\chi$ at $\mathrm{mp}+5{ }^{\circ} \mathrm{C}(\mathrm{mS} / \mathrm{cm})$ & $10.0\left(110^{\circ} \mathrm{C}\right)$ & $0.23\left(40^{\circ} \mathrm{C}\right)$ & $0.22\left(23^{\circ} \mathrm{C}\right)$ & $0.18\left(60{ }^{\circ} \mathrm{C}\right)$ & $0.44\left(80^{\circ} \mathrm{C}\right)$ \\
\hline Viscosity $\mu$ (Pa s) at $\mathrm{mp}+5^{\circ} \mathrm{C}$ shear rate $=0(\mathrm{~b})$ & $0.1\left(110^{\circ} \mathrm{C}\right)$ & $0.2\left(40{ }^{\circ} \mathrm{C}\right)$ & $0.5\left(23^{\circ} \mathrm{C}\right)$ & ca. $4\left(60^{\circ} \mathrm{C}\right)$ & $>5\left(80^{\circ} \mathrm{C}\right)$ \\
\hline Electrochemical window $\Delta E$ anode $(\mathrm{V})$ & 2.3 & n.e. & 2.3 & n.e. & 2.3 \\
\hline Electrochemical window $\Delta E$ cathode $(\mathrm{V})$ & -3.2 & n.e. & -3.2 & n.e. & -3.2 \\
\hline
\end{tabular}

(a) Batch reactor; (b) see Figure 3; (c) n.e.: not examined.
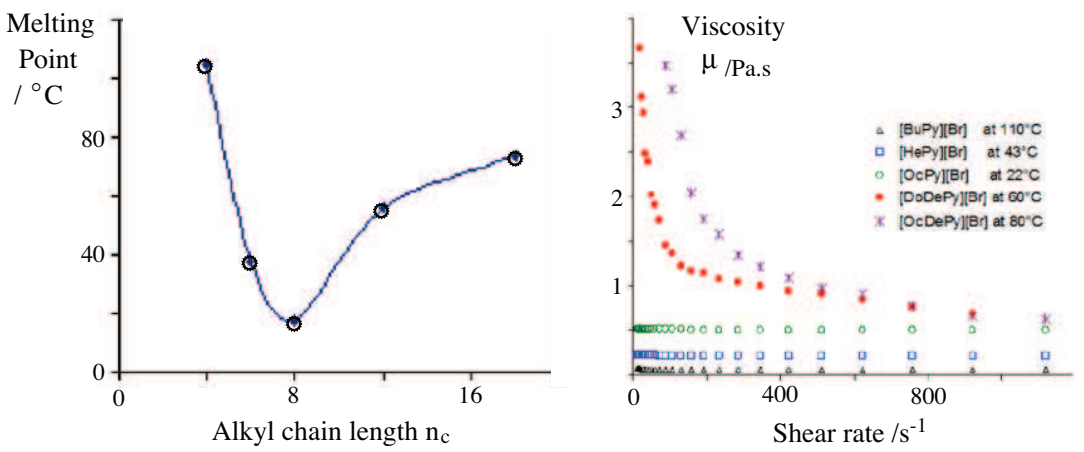

Figure 3. Left: Melting points of alkylpyridinium ILs against alkyl chain length; experimental uncertainty of $\pm 2{ }^{\circ} \mathrm{C}$. Right: Viscosity (measured at ILs melting point $+5{ }^{\circ} \mathrm{C}$ ) dependency vs shear rate for various alkylpyridinium IL.

significant differences between conversions obtained with both reactors.

The matrix of interconnected channels allows reaching a surface/volume ratio $(S / V)$ of $24 \mathrm{~cm}^{2} / \mathrm{cm}^{3}$, whereas for stirred reactor this ratio does not exceed $8 \mathrm{~cm}^{2} / \mathrm{cm}^{3}$. The high specific area of the Hex/MSR offers a better heat transfer thus maintaining a constant temperature anywhere in the reactor and consequently slightly improving conversion, as shown by the comparison of conversion rates obtained at temperatures lower than $80^{\circ} \mathrm{C}$. However at higher temperature there is competition between both reactors.
The large surface offered by Hex/MSR allows a better heat transfer that promote reaction rate more than in stirred reactor at temperatures lower than $80^{\circ} \mathrm{C}$. Nevertheless, it is important to maintain important volumetric flows in order to avoid accumulation of ILs' drops within the microchannels, which have a negative effect in heat transfer.

In conclusion, a family of alkylpyridinium bromide ILs having different alkyl chains length have been synthesized in the scale of a few ten grams and characterized by the measurement of various physico-chemical properties. Melting points and viscosities of 

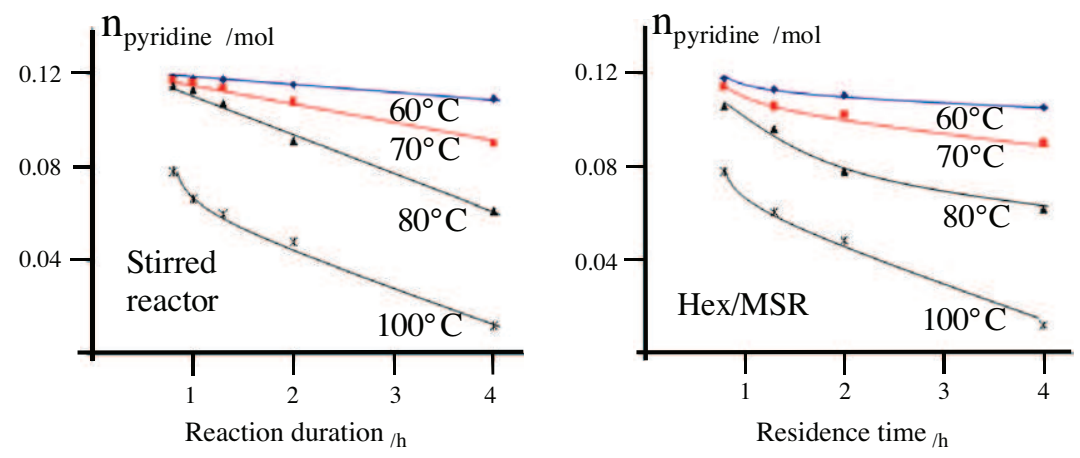

Figure 4. Conversion rate of [OcPy] $\mathrm{Br}]$ synthesis reaction at different temperatures against: reaction duration in stirred reactor (left) and residence time in Hex/MSR (right). $n_{\text {reagents: }} 0.126 \mathrm{~mol}$.

these pyridinium ILs are highly dependent on the alkyl chain length. The potential to intensify liquid phase reaction by use of a Hex/MSR has been investigated using the alkylation of the most representative model reaction (pyridine/1-bromooctane). The reaction performs better in MSR for shorter duration time and lower temperature. Last but not least, because of the better conversion/selectivity of the Hex/MSR in comparison with the batch reactor, the quantity of organic solvents required for purification of IL is strongly minimized and the process of synthesis significantly improved. ${ }^{13}$

\section{Acknowledgments}

The authors thank the Région Midi-Pyrénées for financial support, and the Solvionic Company for its contribution.

\section{Supplementary data}

Supplementary data associated with this article can be found, in the online version, at http://dx.doi.org/10.1016/j.tetlet.2012.04.119.

\section{References and notes}

1. (a) Wasserscheid, P.; Welton, T. Ionic Liquids in Synthesis, 2nd ed.; Wiley-VCH: Weinheim, 2008; (b) Hallet, J. P.; Welton, T. Chem. Rev. 2011, 111, 3508-3576.

2. Durand, J.; Teuma, E.; Gomez, M. C. R. Chimie 2007, 152-177.

3. (a) Baudequin, C.; Brégeon, D.; Levillain, J.; Guillen, F.; Plaquevent, J.-C.; Gaumont, A.-C. Tetrahedron: Asymmetry 2005, 16, 3921-3945; (b) Plaquevent,
J.-C.; Levillain, J.; Guillen, F.; Malhiac, C.; Gaumont, A.-C. Chem. Rev. 2008, 108, 5035-5060; (c) Prechtl, M. H. G.; Scholten, J. D.; Neto, B. A. D.; Dupont, J. Curr. Org. Chem. 2009, 13, 1259-1277.

4. Forsyth, S. A.; Pringle, J. M.; MacFarlane, D. R. Aust. J. Chem. 2004, 57, 113-119.

5. (a) Dautzenberg, F. M.; Mukherjee, M. Chem. Eng. Sci. 2001, 56, 251-267; (b) Stankiewicz, A. Chem. Eng. Process. 2003, 42, 137-144; (c) Harmsen, G. J.; Chewter, L. A. Chem. Eng. Sci. 1999, 54, 1541-1545.

6. Jähnisch, K.; Baerns, M.; Hessel, V.; Löwe, H. Angew. Chem., Int. Ed. 2004, 43, 406-446.

7. Ehrfeld, W.; Hessel, V.; Haverkamp, V. Microreactors, in Ullman's Encyclopedia of Industrial Chemistry; Wiley-VCH: Weinheim, 1999.

8. (a) Waterkamp, D. A.; Engelbert, M.; Thöming, J. Chem. Eng. Technol. 2009, 32, 1717-1723; (b) Wilms, D.; Klos, J.; Kilbinger, A. F. M.; Löwe, H.; Frey, H. Org. Process Res. Dev. 2009, 13, 961-964; (c) Löwe, H.; Axinte, R. D.; Breuch, D.; Hofmann, C.; Petersen, J. H.; Pommersheim, R.; Wang, A. Chem. Eng. J. 2010, 163, 429-437; (d) Hu, S.; Wang, A.; Löwe, H.; Li, X.; Wang, Y.; Li, C.; Yang, D. Chem. Eng. J. 2010, 162, 350-354.

9. (a) Yoshida, J.-i.; Kim, H.; Nagaki, A. ChemSusChem 2011, 4, 331-340; (b) For an excellent introduction to the synthesis of ILs in microstructured reactors, see: Löwe, H., http://www.holger-loewe.de/AAILS02.pdf.

10. See for example: (a) Zhang, S.; Lu, X.; Zhou, Q.; Li, X.; Zhang, X.; Li, S. Ionic Liquids: Physicochemical Properties; Elsevier, 2009. Chapter 7; (b) Tong, B.; Liu, Q.-S.; Tan, Z.-C.; Welz-Biermann, U. J. Phys. Chem. A 2010, 114, 37823787.

11. Zhang, S.; Sun, N.; He, X.; Lu, X.; Zhang, X. J. Phys. Chem. Ref. Data 2006, 35, 1475-1517.

12. Bonhôte, P.; Dias, A. P.; Papageorgiou, N.; Kalyanasundaram, K.; Gratzel, M. Inorg. Chem. 1996, 35, 1168-1178.

13. For an overview of ionic liquids synthesis using non conventional activation, see: (a) Lévêque, J.-M.; Estager, J.; Draye, M.; Cravotto, G.; Boffa, L.; Bonrath, W. Monatsh. Chem. 2007, 138, 1103-1113; For solvent-free and microwave irradiation synthesis of ionic liquids, see: (b) Deetlefs, M.; Seddon, K. R. Green Chem. 2003, 5, 181-186; (c) Cravotto, G.; Gaudino, E. C.; Boffa, L.; Lévêque, J.-M.; Estager, J.; Bonrath, W. Molecules 2008, 13, 149-156; (d) Aupoix, A.; Pégot, B.; Vo-Thanh, G. Tetrahedron 2010, 66, 1352-1356. 